J Arid Land (2013) 5(3): 331-339

doi: $10.1007 / \mathrm{s} 40333-013-0168-9$

jal.xjegi.com; www.springer.com/40333

\title{
Persistence of four dominant psammophyte species in central Inner Mongolia of China under continual drought
}

\author{
YuanRun ZHENG ${ }^{1 *}$, LianHe JIANG $^{2}$, Yong GAO ${ }^{3}, \mathrm{Xi} \mathrm{CHEN}^{4}, \mathrm{GePing} \mathrm{LUO}^{4}$, XianWei FENG ${ }^{4}$, YunJiang \\ $Y^{5}$, Ping $A N^{6}$, Yi YU ${ }^{7}$, Hideyuki SHIMIZU ${ }^{7}$ \\ ${ }^{1}$ Key Laboratory of Resource Plants, Beijing Botanical Garden, Institute of Botany, Chinese Academy of Sciences, Beijing 100093 , \\ China; \\ ${ }^{2}$ State Key Laboratory of Vegetation and Environmental Change, Institute of Botany, Chinese Academy of Sciences, Beijing 100093, \\ China; \\ ${ }^{3}$ Inner Mongolia Agricultural University, Hohhot 010018, China; \\ ${ }^{4}$ Xinjiang Institute of Ecology and Geography, Chinese Academy of Sciences, Urumqi 830011, China; \\ ${ }^{5}$ Chinese Research Academy of Environmental Sciences, Beijing 100012, China; \\ ${ }^{6}$ Arid Land Research Center, Tottori University 1390 Hamasaka, Tottori 680-0001, Japan; \\ ${ }^{7}$ National Institute for Environmental Studies, Tsukuba 305-8506, Japan
}

\begin{abstract}
Clarifying the persistence time of seedlings of dominant species under continual drought will help us understand responses of ecosystems to global climate change and improve revegetation efforts. Drought tolerance of four dominant psammophytic shrub species occurring in different environments was studied in the semi-arid areas of Inner Mongolian grasslands. Seedlings of Hedysarum laeve, Caragana korshinskii, Artemisia sphaerocephala and Artemisia ordosica were grown under four air temperature regimes (night/day: $12.5 / 22.5^{\circ} \mathrm{C}, 15 / 25^{\circ} \mathrm{C}$, $17.5 / 27.5^{\circ} \mathrm{C}$ and $20 / 30^{\circ} \mathrm{C}$ ) within climate (air temperature and humidity) controlled, naturally lit glasshouses with a night/day relative humidity of $70 \% / 50 \%$. Pots were watered to field capacity for each temperature treatment. Soil water condition was monitored by weighting each pot every day using an electronic balance. Date of seedling death for each treatment was recorded and the dead plants were harvested. Plant dry weights were determined after oven drying at $80^{\circ} \mathrm{C}$ for 3 days. Two Artemisia species had higher growth rates than $H$. laeve and $C$. korshinskii, and the growth of all four species increased with increasing temperatures. The two Artemisia species had the highest leaf biomass increment, followed by $C$. korshinskii, and then $H$. laeve. Shoot biomass increment was higher for $A$. ordosica and $C$. korshinskii, intermediate for $A$. sphaerocephala and lowest for $H$. laeve. C. korshinskii had the highest root biomass increment. The final soil water content at death for all four species varied from $1 \%$ to $2 \%$. C. korshinskii, A. sphaerocephala, $H$. laeve and $A$. ordosica survived for $25-43,24-41,26-41$, and 24-37 days without watering, respectively. C. korshinskii, A. sphaerocephala, H. Laeve, and A. ordosica seedlings survived longer at the lowest temperatures $\left(12.5 / 22.5^{\circ} \mathrm{C}\right)$ than at the highest temperatures $\left(20 / 30^{\circ} \mathrm{C}\right)$ by $18,17,15$ and 13 days, respectively. Increased climatic temperatures induce the death of seedlings in years with long intervals between rainfall events. The adaptation of seedlings to droughts should be emphasized in revegetation efforts in the Ordos Plateau, Inner Mongolia.
\end{abstract}

Keywords: biomass allocation; drought; temperature; persistence time; semi-arid area

Citation: YuanRun ZHENG, LianHe JIANG, Yong GAO, Xi CHEN, GePing LUO, XianWei FENG, YunJiang YU, Ping AN, Yi YU, Hideyuki SHIMIZU. 2013. Persistence of four dominant psammophyte species in central Inner Mongolia of China under continual drought. Journal of Arid Land, 5(3): 331-339.

During the last 30 years, environmental problems have gradually constrained sustainable social and economic development in China. Desertification is regarded as a major environmental issue in Northern

*Corresponding author: YuanRun ZHENG (E-mail: zhengyr@ibcas.ac.cn)

Received 2012-12-24; revised 2013-02-06; accepted 2013-02-21

(C) Xinjiang Institute of Ecology and Geography, Chinese Academy of Sciences, Science Press and Springer-Verlag Berlin Heidelberg 2013 
China, especially in Inner Mongolia (Zha and Gao, 1997; Luo et al., 2012; Zhang et al., 2012). Vegetation rehabilitation using dominant species has long been used (China National Committee for the Implementation of the UN Convention to Combat Desertification, 1992) based on field distribution information of indigenous species in areas with different stages of desertification that are characterized by a variety of soil nutrient conditions and varying levels of water availability. Hedysarum laeve Maxim. (Leguminosae) and Artemisia sphaerocephala Krasch. (Asteraceae) are mainly distributed in drifting dunes and semi-fixed dunes while Caragana korshinskii Kom. (Leguminosae) and Artemisia ordosica Krasch. are mainly found in fixed dunes and are the most commonly used species for revegetation. They are typically seeded using dispersal by airplane or by seedling transplantation from nursery stock for revegetation efforts. However, the success of such revegetation has been missed because seedlings often die as a result of drought (Qi, 1998). Adequate knowledge of soil drought tolerance behavior for these four species may allow more efficient use of these species in revegetation. Therefore, the drought tolerance of these species should be clarified.

Young plants are usually used in reforestation of degraded areas. Knowing the extent to which saplings of potentially suitable species are vulnerable to drought stress during the early phases of their development is important (Lo Gullo et al., 2003). Seedling growth is a critical life history stage during which plants are often subjected to high mortality rates (Geraldine and Lisa, 1999; Padilla and Pugnaire, 2007). Seedlings of different species die from a wide variety of causes (Fenner and Kitajima, 1999; Moles and Westoby, 2004). Although many factors may affect seedling survival in desert environment, high temperature on sand surface in the day time and soil desiccation were regarded more important than other factors (Maun, 1998). Temperature fluctuation and soil water dynamics are affected by annual climatic variation (Lawrence and Slingo, 2004; Ziche and Overdieck, 2004; Johnsen et al., 2005). High soil moisture deficit near the soil surface is common in the areas with dunes, whereas moisture levels in deep soil may be sufficient for seedling survival. Plants with a well-established root system can use sporadic supplies of available soil moisture and thus maintain stomatal conductance and leaf turgor, despite the fact that a large portion of the root system grow in dry soil (Kirkham, 1980; Gallardo et al., 1994). Arid and semi-arid desert environments, characterized by unpredictable precipitation events and long intervals between rainfall events, often experience soil desiccation (Middleton and Thomas, 1997).

Plants distributed in areas with limited water availability are expected to have the ability to adjust water use either by increasing biomass production of leaf, shoot or root, or use of other drought tolerance methods (Jones, 1993; Heilmeier, 2002). The balance between biomass allocation and photosynthetic vs. heterotrophic tissue production can also affect the ability of plants to tolerate soil desiccation (Waring and Schlesinger, 1985; Gower et al., 1995). For example, in warm, dry environments, trees allocate proportionally more biomass to sapwood and less to foliage than in cooler, more moist environments, when comparing different species (Waring and Schlesinger, 1985) and within a single species (Callaway et al., 1994).

Numerous studies documented plant responses to soil water availability and soil desiccation. Salleo and Lo Gullo (1993) examined drought resistance of 2-year-old saplings of Ceratonia siliqua, Quercus suber and $Q$. pubescens growing in fields in Sicily, with the aim of estimating their possible use in reforestation of degraded areas. Swemmer et al. (2006) found that Andropogon gerardii adapted to soil drought in the mesic grasslands of the central plains of North America by allocating greater amount of biomass to roots, while reducing allocation to flowering and experiencing more rapid leaf turnover and more rapid recovery of photosynthesis after wilting. Finally, they concluded the latter two traits may be particularly important in conditions of variable soil moisture. Heilmeier et al. (2002) examined the growth of Prunus dulcis grown in the Negev Desert in areas with different water availability by lysimeter and concluded this species did not adapt physiologically to a limited water supply, but maximized their carbon gain for a given amount of water available by phenological 
processes, such as high growth rates during periods of low evaporative demand from the atmosphere. However, knowledge on soil drought tolerance for the four dominant species studied here is inadequate, and these species are distributed in areas in different stages of desertification and therefore may have different mechanisms for soil drought tolerance. Furthermore, drought and high temperature usually occur simultaneously (Machado and Paulsen, 2001). Few studies have considered the combined effects of temperature and soil water content on plant growth (Gill et al., 2001; Hood, 2001). However, plant responses to one stress might be altered by the level of the other stress (Blum et al., 1990; Wang et al., 2011; Zhou et al., 2011). The objective of this study was to investigate the response of growth, biomass allocation and persistence time to soil water dynamics during continual soil drought for the four above-mentioned species under different air temperature conditions. The following questions were posed: (1) How long can these species persist under continual soil drought? (2) How does temperature affect the soil drought tolerance of these species?

\section{Materials and methods}

\subsection{Plant materials}

Seeds of four species, C. korshinskii, H. laeve, A. sphaerocephala and A. ordosica were collected in the $\mathrm{Mu}$ Us Sandy Land. Twenty randomly selected sampling quadrates for each of the four species were used as replicates to get an adequate representation of genetic variation (Zheng et al., 2003). Seeds were collected in 2002, and then transported to Japan, where the experiments were later conducted. Seeds were stored at $4^{\circ} \mathrm{C}$ until they were sown. PVC pots $(11.2$ $\mathrm{cm}$ in diameter and $20 \mathrm{~cm}$ in height) were filled with prepared sand, which had been collected from riverbeds in Japan and washed several times with tap water. The prepared sand used here had been mixed from different particle size groups with proportions similar to the field condition of the study area (Qi, 1998). The composition percentages (percent of gravimetric content) for the four size groups $(>0.5,0.5-0.25,0.25-0.1$, and $0.1-0.05 \mathrm{~mm})$ were $(3.3 \pm 1.1) \%,(45.0 \pm 3.7) \%$,
$(47.3 \pm 2.4) \%$, and $(2.4 \pm 0.5) \%$, respectively. Finally, the prepared sand was mixed with artificial clay $(20 \%$ of total volume) (Bonsai mixture Earth, P-Iwamoto Inc., Ibaraki, Japan). The drainage outlet at the bottom of the pots was covered with strips of nylon mesh to prevent the loss of sand while allowing drainage of excess water. The seedlings emerged within 15 days, were then transplanted to pots and left for 30 days with normal irrigation before the experiment began.

\subsection{Experimental design}

Experiments were carried out within climate (air temperature and humidity) controlled, naturally lit glasshouses with a night/day relative humidity of $70 \%$ / $50 \%$.

Four air temperature regimes (night/day: 12.5/ $22.5^{\circ} \mathrm{C}, 15 / 25^{\circ} \mathrm{C}, 17.5 / 27.5^{\circ} \mathrm{C}$ and $20 / 30^{\circ} \mathrm{C}$ ), which caused different rates of soil drying throughout the experiment, were assigned to four glasshouses. The control treatment regimes $\left(12.5 / 22.5^{\circ} \mathrm{C}\right.$ and $\left.15 / 25^{\circ} \mathrm{C}\right)$ were designed according to the monthly average temperature in the main growing season $\left(12.5 / 22.5^{\circ} \mathrm{C}\right.$ and $15 / 25^{\circ} \mathrm{C}$ from mid-June to mid-August) in the $\mathrm{Mu}$ Us Sandy Land, based on the 30-year average of microenvironmental data (Qi, 1998). Pots were watered to field capacity for each temperature treatment. There were 12 replicates (each replicate had one pot with one seedling) per treatment for each species (12 replicates of four treatments for four species). At the beginning of the experiment, 12 additional plants of each species were harvested immediately to provide initial growth data to be used for the final growth analysis in each treatment (Xiong et al., 2000). Pots with seedlings were randomly assigned to each treatment and pots were randomly relocated every three days. Plants had sufficient space to prevent shading of smaller plants by larger ones (Clifton-Brown and Lewandowski, 2000). Soil water condition was monitored by weighing each pot every day using an electronic balance.

The date of seedling death for each treatment was recorded and the dead plants were harvested. These plants were divided into roots, shoots and leaves, including dropped leaves and remaining leaves. Soil was washed from roots by hand. Dry weights were determined after oven drying at $80^{\circ} \mathrm{C}$ for 3 days. 


\subsection{Growth analysis}

The relative growth rate (RGR) of each plant was estimated using Eq. 1:

$$
R G R=\frac{1}{t_{2}-t_{1}} \int_{w_{1}}^{w_{2}} d(\ln w)=\frac{\ln w_{2}-\ln w_{1}}{t_{2}-t_{1}} .
$$

Where $w_{1}$ and $w_{2}$ are plant dry mass at the initial time $\left(t_{1}\right)$ and at the final harvest $\left(t_{2}\right)$, respectively (Hunt, 1990; Xiong et al., 2000).

\subsection{Statistical analysis}

Data were $\log$ transformed prior to statistical analysis to ensure homogeneity of variance (Carey et al., 1998). The transformed values were analyzed using two-way analysis of variance (ANOVA). If significant differences were found, Tukey's test was used to determine the mean differences between treatments (Chen and Maun, 1999). All statistical analyses, including the test for homogeneity of variance, were performed using the SPSS 10.0 package (SPSS Inc., Chicago, Illinois, USA).

\section{Results}

$F$-statistic values were significant for species and temperature for almost all growth variables except the effect of species on soil moisture. The interaction had only significant effects on relative growth rate (RGR), persistence time and shoot biomass increment (Table 1).

\subsection{Biomass increment and relative growth rate}

Generally, root and shoot biomass increment was higher at lower temperatures $\left(12.5 / 22.5^{\circ} \mathrm{C}\right)$ for the four species. There was no significant effect of temperature on leaf biomass increment for the two $A r$ - temisia species. Leaf biomass increment was higher at higher temperatures for C. korshinskii (Fig. 1). The two Artemisia species had the highest leaf biomass increment $(0.18-0.27 \mathrm{~g})$, followed by $C$. korshinskii (0.03-0.11 g), and then H. laeve $(0.01-0.04 \mathrm{~g})$. Shoot biomass increment was higher for $A$. ordosica and $C$. korshinskii, intermediate for A. sphaerocephala and lowest for H. laeve. C. korshinskii had the highest root biomass increment. The RGR generally increased with increasing temperatures for all four species. The RGR was much higher for the two Artemisia species than for H. laeve and C. korshinskii (Fig. 2).

\subsection{Dry matter allocation}

The ratio of below-ground to above-ground dry matter was lower for the two Artemisia species $((0.10-$ $0.15): 1)$ than for $C$. korshinskii and H. laeve $((0.30$ 0.57):1). Temperature had no significant effects on that ratio for the two Artemisia species, while the ratio decreased with increasing temperatures for C. korshinskii and H. laeve (Fig. 3).

\subsection{Persistence time}

The persistence time decreased with increasing temperatures for all four species. Persistence time was the highest for $C$. korshinskii (25-43 days), lowest for $A$. ordosica (24-37 days) and intermediate for $A$. sphaerocephala (24-41 days) and $H$. laeve (26-41 days) (Fig. 4).

\subsection{Gravimetric soil water content}

There was no significant difference in the final soil water content (varying from $1 \%-2 \%$ ) for all four species at the point when seedlings died. However, soil water content decreased faster for the two Artemisia species than for H. laeve and C. korshinskii (Fig. 5).

Table 1 Results of two-way ANOVA of characteristics of biomass increment for leaves, shoot and root, the ratio of below-ground to above-ground dry matter, persistence time, soil moisture, relative growth rate (RGR) and their combinations

\begin{tabular}{lcccccccc}
\hline \multirow{2}{*}{ Effect } & $d f$ & Leaf biomass & Shoot biomass & Root biomass & $\begin{array}{c}\text { Root/shoot } \\
\text { Biomass }\end{array}$ & Persistence time & Soil moisture & RGR \\
\cline { 3 - 8 } & & & \multicolumn{7}{c}{$F$ value } \\
\hline Species (S) & 3 & $95.27^{* * *}$ & $54.49^{* * *}$ & $11.55^{* * *}$ & $89.92^{* * *}$ & $9.13^{* * *}$ & $1.99^{\text {ns }}$ & $141.59^{* * *}$ \\
Temperature (T) & 3 & $1.38^{* * *}$ & $7.28^{* * *}$ & $12.42^{* * *}$ & $7.74^{* * *}$ & $195.01^{* * *}$ & $5.67^{* *}$ & $24.63^{* * *}$ \\
$\mathrm{~S} \times \mathrm{T}$ & 9 & $1.83^{\text {ns }}$ & $2.32^{*}$ & $1.79^{\text {ns }}$ & $1.68^{\text {ns }}$ & $6.32^{* * *}$ & $1.56^{\text {ns }}$ & $4.96^{* * *}$ \\
\hline
\end{tabular}

Note: Seedlings of four species were exposed to four levels of alternating temperatures $\left(12.5 / 22.5^{\circ} \mathrm{C}, 15 / 25^{\circ} \mathrm{C}, 17.5 / 27.5^{\circ} \mathrm{C}, 20 / 30^{\circ} \mathrm{C}\right)$ in naturally lit glasshouses. Significance levels: ***, $P<0.001 ; * *, P<0.01 ; *, P<0.05 ;$ ns, $P \geq 0.05$. 


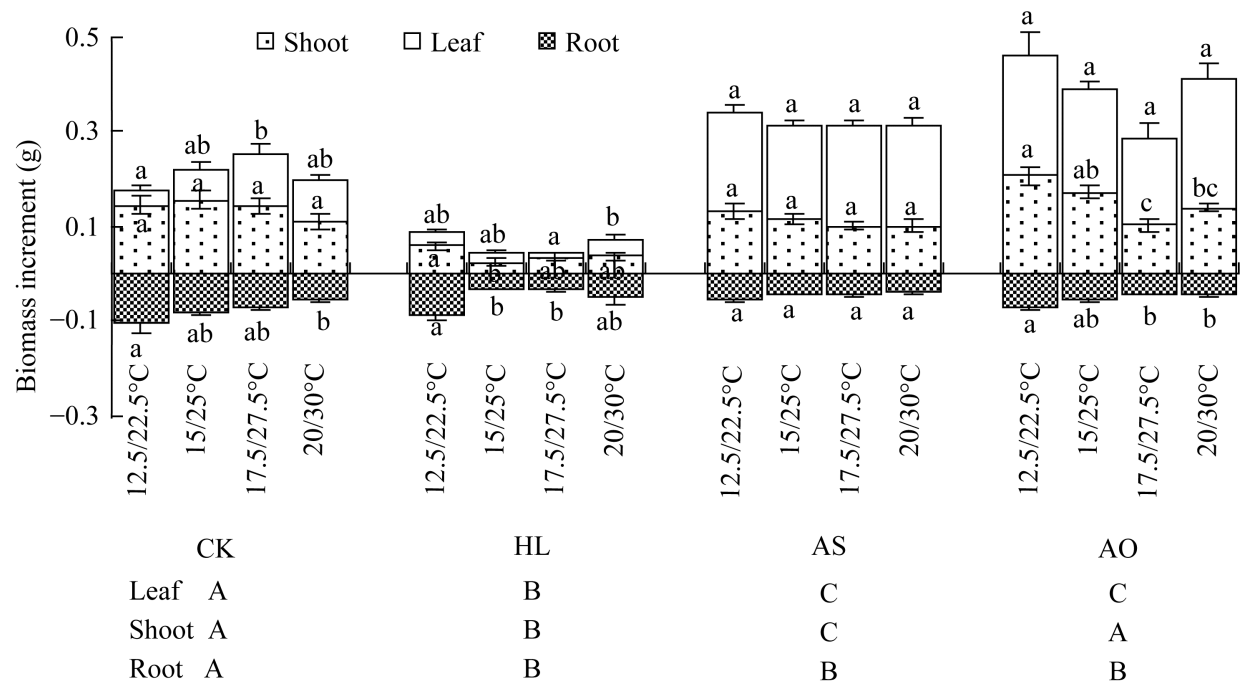

Fig. 1 Biomass increment (mean \pm SE) of Caragana korshinskii (CK), Hedysarum laeve (HL), Artemisia sphaerocephala (AS), and Artemisia ordosica $(\mathrm{AO})$ under alternating temperatures (night/day: $12.5 / 22.5^{\circ} \mathrm{C}, 15 / 25^{\circ} \mathrm{C}, 17.5 / 27.5^{\circ} \mathrm{C}, 20 / 30^{\circ} \mathrm{C}$ ). Bars with different lowercase letters are significantly different from each other with different temperatures for same species, and different capital letters indicate difference between species at $P<0.05$ (Tukey's Test) $(n=12)$.

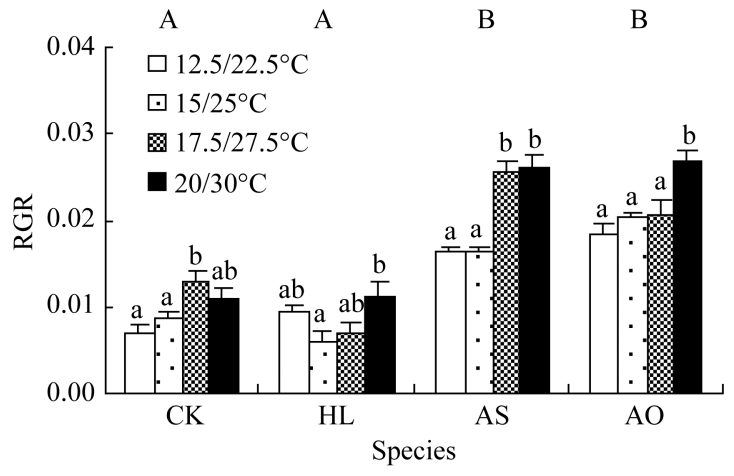

Fig. 2 The relative growth rate (RGR) (mean $\pm S E)$ of four species. Other descriptions are the same as in Fig. 1.

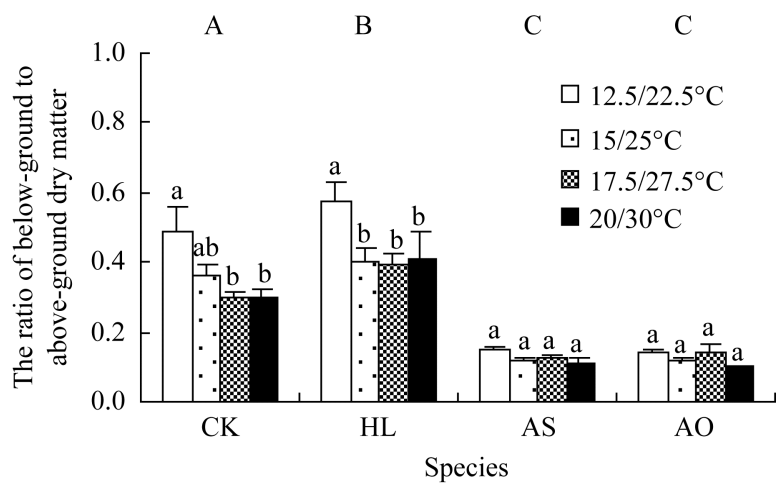

Fig. 3 The ratio of below-ground to above-ground dry matter $($ mean $\pm \mathrm{SE})$ of four species. Other descriptions are the same as in Fig. 1.

\section{Discussion and conclusions}

Drought has substantial and negative influences on

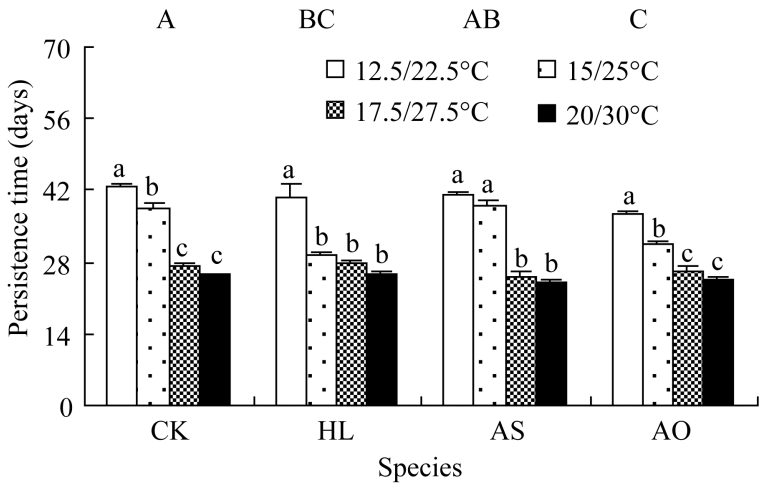

Fig. 4 Persistence time (mean \pm SE) of four species. Other descriptions are the same as in Fig. 1.

many processes (Qaderi et al., 2006). Heilmeier (2002) reported plants tend to accelerate growth under drought. This adaptive mechanism is especially important for some short-lived desert plants that fulfill their life cycle after a single rainfall event or during a short rainy season (Maun, 1998). The studied four species may have evolved similar mechanisms to adapt to fluctuating and unpredictable rainfall in the Mu Us Sandy Land (Qi, 1998). Plants grown under high temperatures had lower biomass than those grown under low temperatures (Qaderi et al., 2006). This was also true especially for the two Artemisia species in our study, although their total biomass increment was high (0.4-0.53 g) at the lowest tempera- 

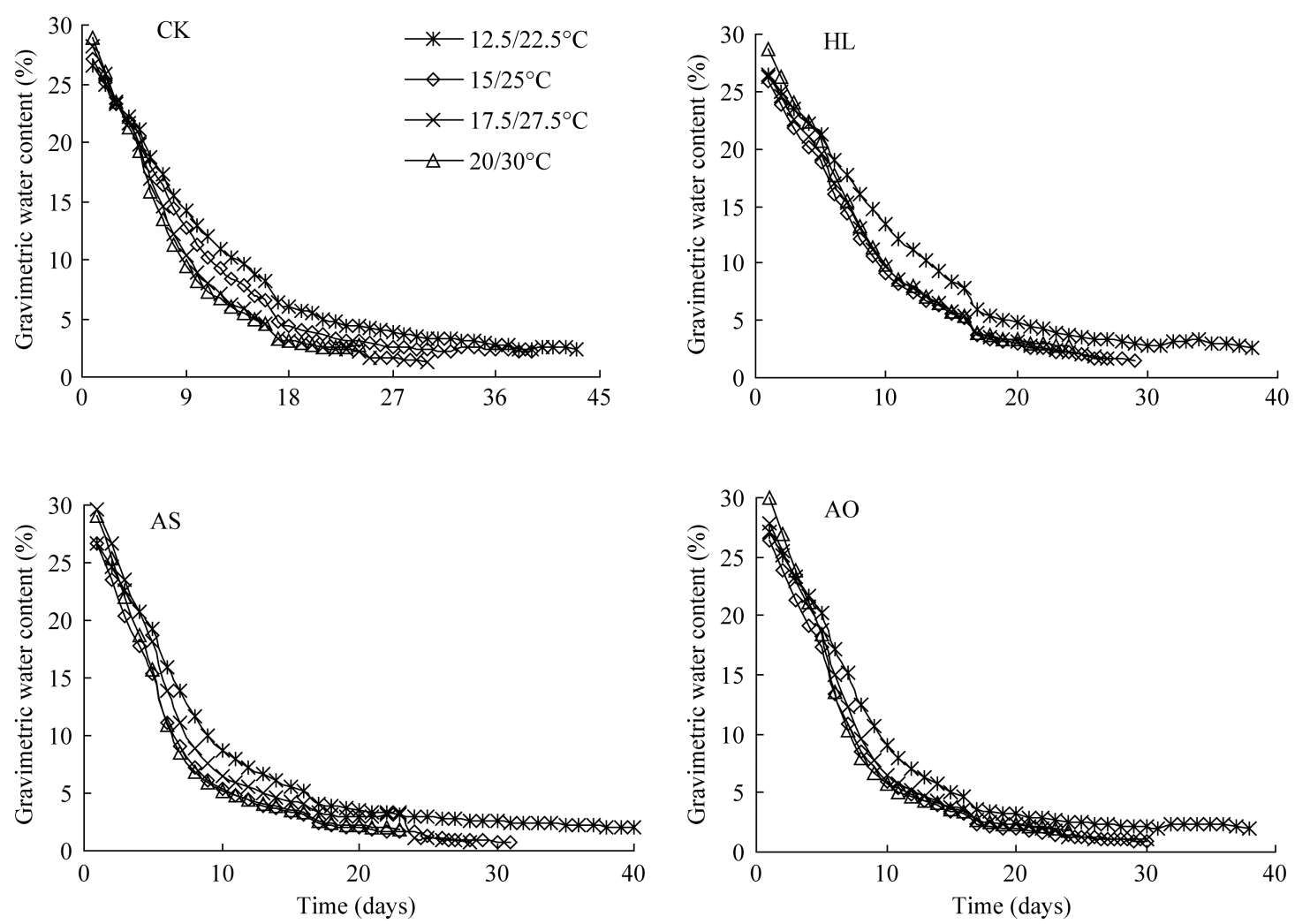

Fig. 5 The course of gravimetric soil water content (mean \pm SE) for four species. Other descriptions are the same as in Fig. 1.

tures $\left(12.5 / 22.5^{\circ} \mathrm{C}\right)$ and low $(0.35-0.46 \mathrm{~g})$ at the highest temperatures $\left(20 / 30^{\circ} \mathrm{C}\right)$. However, the RGR was 1.5 times larger at higher temperatures $\left(20 / 30^{\circ} \mathrm{C}\right)$ than at lower temperatures $\left(12.5 / 22.5^{\circ} \mathrm{C}\right)$ (Fig. 2).

Plants may adjust to resource imbalances by allocating biomass to organs that acquire the limiting resource (Chapin et al., 1987), so plants are expected to have a high ratio of below-ground to above-ground dry matter during periods of water stress (Waring and Schlesinger, 1985; Wilson, 1988; Padilla and Pugnaire, 2007). In our experiment, the two Artemisia species allocated more biomass to their above-ground components, whereas $C$. korshinskii and $H$. laeve allocated more biomass to their below-ground components. However, we observed that the ratio of below-ground to above-ground dry matter of $C$. korshinskii and $H$. laeve decreased with increasing temperatures. For example, this ratio decreased from $0.49: 1.00$ $\left(12.5 / 22.5^{\circ} \mathrm{C}\right)$ to $0.3: 1.0\left(20 / 30^{\circ} \mathrm{C}\right)$ for C. korshinskii and from $0.57: 1.00\left(12.5 / 22.5^{\circ} \mathrm{C}\right)$ to $0.41: 1.00$ $\left(20 / 30^{\circ} \mathrm{C}\right)$ for $H$. laeve. Although there was no significant effect for both Artemisia species, the ratio of below-ground to above-ground dry matter also tended to decrease with increasing temperatures. This may be because plants allocate more biomass to photosynthetic organs to accelerate growth under soil water drought (Heilmeier, 2002).

The point at which soil water content induced plant death was not significantly different for all four species (Fig. 5). This indicated that seedlings of different species may have similar permanent wilting points, because the seedlings of all four species should develop to specific stage (i.e. adult plants rather than seedlings), enabling them to tolerate drought through their morphological and physiological adjustments, such as modified leaf water potential and/or osmotic potential (Manivannan et al., 2007). This indicated that seedling recruitment is a critical stage in plant life history because high mortality rates are often associated with the seedling phase (Padilla and Pugnaire, 2007), and therefore seedlings behaved in different ways compared with adult plants (Maun, 1998).

The seedling persistence time was affected by both species and temperature (Fig. 4). The severity of the drought effect appears to be dependent on temperature (Machado and Paulsen, 2001). Temperature influences 
drought stress by affecting the availability of soil water. High temperature accelerates the depletion of soil water when the water supply is reduced (Kramer, 1980; Kumer et al., 1985). Our results indicated that temperature could significantly decrease the persistence time for different species. The persistence time was 18 days longer at the lowest temperatures $\left(12.5 / 22.5^{\circ} \mathrm{C}\right)$ than at the highest temperatures $\left(20 / 30^{\circ} \mathrm{C}\right)$ for $C$. korshinskii, and 15, 17 and 13 days longer for $H$. laeve, $A$. sphaerocephala and $A$. ordosica, respectively, because high evapotranspiration and high RGRs consume more water at the highest temperatures and consequently resulted in short persistence time.

In desert environments, drought is often accompanied by high temperatures and the unpredictable interval between two rainfall events (Repellin et al., 1997). In the practice of revegetation (usually conducted in May and early June) in the Mu Us Sandy Land, seedlings usually were well-watered immediately after they were transplanted from the nursery. Therefore, successful establishment of seedlings depended on rainfall intensity and rainfall intervals. Rainfall from May to June during 1995-2004 accounted for $3 \%-32 \%$ of the annual rainfall in the $\mathrm{Mu}$ Us Sandy Land, and varied from 9.6-151.6 mm. The minimum interval between two rainfall events was greater than 10 days except during 2003. The interval was over 15 days in most years, and even reached 29 days in 1996 when rainfall was low. More seriously, the measured rainfall was only $9.6 \mathrm{~mm}$ and was spread out by intervals of 11,16 and 23 days during two months in 2001 (Table 2). Our result showed that planted seedlings well watered only once could survive under $12.5 / 22.5^{\circ} \mathrm{C}$ and $15 / 25^{\circ} \mathrm{C}$. Global general circulation models have predicted average global surface air warming of $1.5^{\circ} \mathrm{C}$ to $5.2^{\circ} \mathrm{C}$, if the ambient $\mathrm{CO}_{2}$ concentration doubled (Mitchell, 1989; Saralabai et al., 1997). If rainfall patterns remain unchanged, seedlings of these four species may not survive in a situation similar to that which occurred in 1996, and may encounter very severe problems surviving in situations similar to those in 1995, 1997 and 2001, when the rainfall interval exceeded 21 days. However, the exact persistence time may be different considering soil characteristics used in this experiment and in the filed. To increase the possibility of successful revegetation, the timing of seedlings transplanting should be considered based on climate and through the use of seedlings of species such as C. korshinskii, which have longer persistence time during drought.

Table 2 Total rainfall and interval between two rainfall events from May to June during 1995-2004 in Mu Us Sandy Land

\begin{tabular}{|c|c|c|c|c|c|c|c|c|c|c|c|c|c|}
\hline \multirow{2}{*}{$\frac{\text { Year }}{1995}$} & \multicolumn{12}{|c|}{ Interval between two rainfall events (days) } & \multirow{2}{*}{$\frac{\text { Total rainfall }(\mathrm{mm})}{23.0}$} \\
\hline & 7 & 2 & 22 & 7 & 3 & & & & & & & & \\
\hline 1996 & 29 & 4 & 2 & 8 & 2 & 2 & 7 & & & & & & 51.9 \\
\hline 1997 & 4 & 2 & 15 & 7 & 3 & 21 & & & & & & & 71.0 \\
\hline 1998 & 3 & 2 & 3 & 6 & 6 & 5 & 6 & 7 & 16 & & & & 93.5 \\
\hline 1999 & 15 & 4 & 9 & 6 & 3 & 5 & & & & & & & 77.9 \\
\hline 2000 & 15 & 7 & 3 & 10 & 4 & 4 & & & & & & & 34.7 \\
\hline 2001 & 23 & 16 & 11 & & & & & & & & & & 9.6 \\
\hline 2002 & 2 & 2 & 5 & 19 & 9 & 3 & 5 & & & & & & 151.6 \\
\hline 2003 & 7 & 2 & 2 & 3 & 5 & 3 & 6 & 9 & 3 & 2 & 2 & 4 & 107.1 \\
\hline 2004 & 12 & 2 & 8 & 2 & 8 & 7 & 2 & 4 & 8 & & & & 73.1 \\
\hline
\end{tabular}

\section{Acknowledgments}

This work was supported by the National Basic Research Program of China (2009CB825103).

\section{References}

Blum A, Ramaiah S, Kanemasu E T, et al. 1990. The physiology of heterosis in sorghum with respect to environmental stress. Annals of 
Botany, 65: 149-158.

Callaway R M, Delucia E H, Schlesinger W H. 1994. Biomass allocation of montane and desert ponderosa pine: an analog for response to climate change. Ecology, 75: 1474-1481.

Carey E V, Callaway R M, DeLucia E H. 1998. Increased photosynthesis offsets cost of allocation to sapwood in an arid environment. Ecology, 79: 2281-2291.

Chapin F S III, Bloom A J, Field C B, et al. 1987. Plant responses to multiple environmental factors. Bioscience, 37: 49-57.

Chen H, Maun M A. 1999. Effects of sand burial depth on seed germination and seedling emergence of Cirsium pitcheri. Plant Ecology, 140: 53-60.

China National Committee for the Implementation of the UN Convention to Combat Desertification. 1992. China National Action Program to Combat Desertification. Beijing: Ministry of Forestry.

Clifton-Brown J C, Lewandowski I. 2000. Water use efficiency and biomass portioning of three different Miscanthus genotypes with limited and unlimited water supply. Annals of Botany, 86: 191-200.

Fenner M, Kitajima K. 1999. Seed and seedling ecology. In: Pugnaire F I, Valladares F. Handbook of Functional Pant Ecology. New York: Marcel Dekker Inc.

Gallardo M, Turner N C, Ludig C. 1994. Water relations, gas exchange and abscisic acid content of Lupinus cosentinii leaves in response to drying different proportions of the root system. Journal of Experimental Botany, 45: 909-918.

Geraldine L D, Lisa A D. 1999. Water potential and ionic effects on germination and seedling growth of two cold desert shrubs. American Journal of Botany, 86: 1146-1153.

Gill J S, Sivasithamparam K, Smettem K R J. 2001. Effect of soil moisture at different temperatures on Rhizoctonia root rot of wheat seedlings. Plant and Soil, 231: 91-96.

Gower S T, Isebrands J G, Sheriff D W. 1995. Carbon allocation and accumulation in conifers. In: Smith W K, Hinckley T M. Resource Physiology of Conifers: Acquisition, Allocation, and Utilization. New York: Academic Press.

Heilmeier H, Wartinger A, Erhard M, et al. 2002. Soil drought increases leaf and whole-plant water use of Prunus dulcis grown in the Negev Desert. Oecologia, 130: 329-336.

Hood R C. 2001. The effect of soil temperature and moisture on organic matter decomposition and plant growth. Isotopes in Environmental and Health Studies, 37: 25-41.

Hunt R. 1990. Basic Growth Analysis. London: Unwin Hyman Limited. Johnsen Ø, Dæhlen O G, Østreng G, et al. 2005. Daylength and temperature during seed production interactively affect adaptive performance of Picea abies progenies. New Phytologist, 168(3): 589-596.

Jones H G. 1993. Drought tolerance and water-use efficiency. In: Smith J A C, Griffiths J. Water Deficits: Plant Responses from Cell to Community. Oxford: BIOS.

Kirkham M B. 1980. Movement of cadmium and water in split-root wheat plants. Soil Science, 129: 339-344.

Kramer P J. 1980. Drought stress and origin adaptation. In: Turner N C, Kramer P J. Adaptation of Plants to Water and High Temperature Stress. New York: John Wiley and Sons.

Kumer R, Gagri P R, Prihard S S. 1985. Water use by wheat as affected by soil moisture, rooting, canopy and evaporation. Indian Journal of Agricultural Sciences, 55: 570-573.

Lawrence D M, Slingo J M. 2004. An annual cycle of vegetation in a GCM. Part II: global impacts on climate and hydrology. Climate Dynamics, 22: 107-122.

Lo Gullo M A, Salleo S, Rosso R, et al. 2003. Drought resistance of 2-year-old saplings of Mediterranean forest trees in the field: relations between water relations, hydraulics and productivity. Plant and Soil, 250: 259-272.

Luo G P, Han Q F, Cheng X, et al. 2012. Moderate grazing can promote aboveground primary production of grassland under water stress. Ecological Complexity, 11: 126-136.

Machado S, Paulsen G M. 2001. Combined effects of drought and high temperature on water relations of wheat and sorghum. Plant and Soil, 233: 179-187.

Manivannan P, Abdul J C, Sankar B, et al. 2007. Growth, biochemical modifications and proline metabolism in Helianthus annuus L. as induced by drought stress. Colloids and Surfaces B: Biointerfaces, 59: 141-149.

Maun M A. 1998. Adaptations of plants to burial in coastal sand dunes. Canadian Journal of Botany, 76: 713-738.

Middleton N, Thomas D. 1997. World Atlas of Desertification. London: Arnold.

Mitchell J F B. 1989. The "greenhouse" effect and climate change. Reviews of Geophysics, 27: 115-139.

Moles A T, Westoby M. 2004. What do seedlings die from and what are the implications for evolution of seed size? Oikos, 106: 193-199.

Padilla F M, Pugnaire F I. 2007. Rooting depth and soil moisture control Mediterranean woody seedling survival during drought. Functional Ecology, 21: 489-495.

Qaderi M M, Kurepin L V, Reid D M. 2006. Growth and physiological responses of canola (Brassica napus) to three components of global climate change: temperature, carbon dioxide and drought. Physiologia Plantarum, 128: 710-721.

Qi J. 1998. Aerial Sowing for Sand Control in China. Beijing: Science Press.

Repellin A, Laffray D, Daniel C, et al. 1997. Water relations and gas exchange in young coconut palm (Cocos nucifera L.) as influenced by water deficit. Canadian Journal of Botany, 75: 18-27.

Salleo S, Lo Gullo M A. 1993. Drought resistance strategies and vulnerability to cavitation of some Mediterranean sclerophyllous trees. In: Borghetti M, Grace J, Raschi A. Water Transport in Plants under Climatic Stress. Cambridge: Cambridge University Press.

Saralabai V C, Vivekandan M, Sureshbabu R. 1997. Plant responses to 
high $\mathrm{CO}_{2}$ concentration in the atmosphere. Photosynthetica, 33: $7-37$.

Swemmer A M, Knapp A K, Smith M D. 2006. Growth responses of two dominant $\mathrm{C}_{4}$ grass species to altered water availability. International Journal of Plant Sciences, 167: 1001-1010.

Wang J C, Shi X, Zhang D Y, et al. 2011. Phenotypic plasticity in response to soil moisture availability in the clonal plant Eremosparton songoricum (Litv.) Vass. Journal of Arid Land, 3(1): 34-39.

Waring R H, Schlesinger W H. 1985. Forest Ecosystems Concepts and Management. New York: Academic Press.

Wilson J B. 1988. A review of evidence on the control of shoot:root ratio in relation to models. Annals of Botany, 61: 433-449.

Xiong F S, Mueller E C, Day T A. 2000. Photosynthetic and respiratory acclimation and growth response of Antarctic vascular plants to contrasting temperature regimes. American Journal of Botany, 87: $700-710$.
Zha Y, Gao J. 1997. Characteristics of desertification and its rehabilitation in China. Journal of Arid Environments, 37: 419-432.

Zhang C, Li C F, Chen X, et al. 2013. A spatial-explicit dynamic vegetation model that couples carbon, water, and nitrogen processes for arid and semiarid ecosystems. Journal of Arid Land, 5(1): 102-117.

Zheng Y R, Xie Z X, Gao Y, et al. 2003. Ecological restoration in northern China: germination characteristics of 9 key species in relation to air seeding. Belgian Journal of Botany, 136: 129-138.

Zhou X B, Zhang Y M, Ji X H, et al. 2011. Combined effects of nitrogen deposition and water stress on growth and physiological responses of two annual desert plants in northwestern China. Environmental and Experimental Botany, 74: 1-8.

Ziche D, Overdieck D. 2004. $\mathrm{CO}_{2}$ and temperature effects on growth, biomass production, and stem wood anatomy of juvenile Scots pine (Pinus sylvestris L.). Journal of Applied Botany and Food Quality, 78: $120-132$. 